\title{
A LIBERDADE DE EXPRESSÃO E O CRIME DE DESACATO À LUZ DO SISTEMA INTERAMERICANO DE DIREITOS HUMANOS
}

\author{
Maria Eduarda Dias Fonseca ${ }^{1}$ \\ Cristina Figueiredo Terezo Ribeiro ${ }^{2}$
}

\section{RESUMO}

Diante da importância do direito à liberdade de expressão para a consolidação de uma sociedade democrática, sobretudo no que diz respeito ao controle democrático das atividades estatais, tem-se a necessidade de se discutir acerca dos entendimentos relativos a este direito e as formas de sua restrição. Neste sentido, a proposta do presente artigo é de estudar os entendimentos da Corte Interamericana de Direitos Humanos no que diz respeito à liberdade de expressão, para em seguida observar se o crime de desacato tipificado na legislação brasileira se enquadra nos requisitos das restrições permitidas pelo Sistema Interamericano.

Palavras-chave: Sistema Interamericano de Direitos Humanos; Corte Interamericana; Liberdade de Expressão; Restrições da Liberdade de Expressão; Desacato.

\section{FREEDOM OF EXPRESSION AND THE CRIME OF CONTEMPT IN THE LIGHT OF THE INTER-AMERICAN HUMAN RIGHTS SYSTEM}

\begin{abstract}
In light of the importance of the right to freedom of expression for the consolidation of a democratic society, especially regarding democratic control of state activities, there is a need to discuss the understandings concerning this right and the ways to restrict it. In this sense, the proposal of the present article is to study the understandings of the Inter-American Court of Human Rights in what concerns freedom of expression, in order to then observe if the crime of contempt typified in the Brazilian legislation fits the requirements of the restrictions allowed by the Inter-American System.
\end{abstract}

Keywords: Inter-American System of Human Rights; Inter-American Court; Freedom of Expression; Restrictions of Freedom of Expression; Crime of contempt.

\section{INTRODUÇÃO}

\footnotetext{
${ }^{1}$ Mestranda do Programa de Pós-Graduação em Direito da Universidade Federal do Pará, voluntária da linha de pesquisa "Proteção Internacional de Direitos Humanos" na Clínica de Direitos Humanos da Amazônia, ganhadora do I Torneio Regional de Direitos Humanos promovido pela OAB/PA (2017), ganhadora do "Concurso de Audiencias Temáticas ante la Comisión Interamericana de Derechos Humanos" (2019), realizado pelo Centro Internacional para la Promoción de los Derechos Humanos (CIPDH-UNESCO) e pela Comissão Interamericana de Direitos Humanos (CIDH). (mefonseca29@gmail.com).

2 Doutora em Direito pela Universidade Federal do Pará, Professora do Programa de Pós-Graduação em Direito da Universidade Federal do Pará, Coordenadora da Clínica de Direitos Humanos da Amazônia. (cfterezo@hotmail.com).
} 
Em um Estado democrático, defende-se o conteúdo essencial da manifestação da liberdade, que é assegurado tanto sob o aspecto positivo, ou seja, a proteção da exteriorização da opinião, como sob o aspecto negativo, referente à proibição da censura (MORAES, 2016 apud FERREIRA, 1989, p. 68). Nesse sentido, tem-se a proteção do direito à liberdade de expressão.

A discussão acerca da proteção deste direito e da observância das disposições internacionais acerca do tema se mostra essencial a partir do momento em que fica clara sua necessidade para a concretização de uma sociedade verdadeiramente democrática, visto que são componentes fundamentais do exercício da democracia a transparência das atividades governamentais, a probidade, a responsabilidade dos governos na gestão pública e o respeito pelos direitos sociais (CorteIDH, 2004a).

Segundo Amartya Sen, os direitos políticos, e aqui se inclui a liberdade de expressão, são fundamentais para demandar respostas políticas (SEM in FARMER, 2004). Neste sentido, têm-se a relação estrutural da liberdade de expressão com a democracia, que tem sido qualificada, tanto pela Corte Interamericana de Direitos Humanos (CorteIDH ou Corte) quanto pela Comissão Interamericana de Direitos Humanos (CIDH ou Comissão) como estreita, indissolúvel, indivisível e fundamental (CorteIDH, 1985, 2004a, 2004b; OEA, 2009). No mesmo viés, Flávia Piovesan entende que não há Direitos Humanos sem democracia, tampouco democracia sem Direitos Humanos (PIOVESAN, 2015, p. 50).

Esta estreita relação pode ser percebida tanto na dimensão individual quanto na dimensão social (CorteIDH, 2001b; 2004a) do direito à liberdade de expressão, isto é, pelo direito do indivíduo de manifestar livremente suas ideias e pensamento e pelo direito de difundir e receber ideias e informações, assim como prevê a CorteIDH em sua jurisprudência. Estes elementos são indispensáveis para que a população esteja bem informada e para a formação da opinião pública, para que assim seja realizado o controle democrático das atividades estatais.

É neste contexto que surge a discussão acerca da compatibilidade do crime de desacato com a proteção do direito à liberdade de expressão, visto que a tipificação do delito se apresenta como uma restrição ao exercício deste direito, sobretudo no que diz respeito às questões de interesse público e daquelas relacionadas aos que estão no exercício da função pública. Por este motivo, o presente artigo se propõe a analisar a compatibilidade do crime de desacato com o entendimento da Corte Interamericana de Direitos Humanos, que possui um 
entendimento consolidado acerca do direito à liberdade de expressão e de suas possíveis restrições.

É possível perceber que no âmbito interno ainda não se tem uma discussão aprofundada acerca da proteção deste direito. Isto está aliado ao fato de que os tribunais internos não buscam se utilizar dos parâmetros internacionais estabelecidos pelos documentos que versam sobre Direitos Humanos, sendo raras as decisões que se utilizam das interpretações dos tribunais internacionais e dos documentos internacionais, gerando uma menor proteção de direitos.

Nesse sentido, é importante a observância do estabelecido pelo Sistema Interamericano de Direitos Humanos, aqui representado pela análise da jurisprudência da Corte Interamericana, acerca do direito à liberdade de expressão e das possibilidades e requisitos para sua restrição. Depois desta análise será possível se utilizar destas disposições para averiguar se o crime de desacato está de acordo com a proteção do direito à liberdade de expressão conferido pelo corpus juris interamericano.

Para isso, foi realizada uma pesquisa documental, por meio do estudo das decisões da Corte Interamericana de Direitos Humanos que versam sobre o direito à liberdade de expressão. Em seguida, será analisada a legislação interna acerca do delito de desacato (Constituição Federal e Código Penal Brasileiro), a fim de verificar a compatibilidade destas com o que estabelece a Convenção Americana e a Corte Interamericana.

\section{A LIBERDADE DE EXPRESSÃO}

A liberdade de expressão é um direito por meio do qual se permite a livre difusão de ideias e informações, sendo sua proteção de grande importância em uma sociedade democrática, visto que é por meio do exercício deste direito que a população tem a oportunidade de se manifestar acerca dos acontecimentos que influenciam a vida em sociedade, assim, pode-se dizer que este direito é uma consequência do sistema democrático, visto que contribui para a formação da opinião pública acerca de debates públicos (CHEQUER, 2011, p. 65). Desse modo, tem-se a garantia da participação do povo no processo de autodeterminação democrática (MACHADO, 2002, p.260). 
Dada sua importância, a liberdade de expressão é protegida pelo texto constitucional em seu artigo $5^{\circ}$, IV e IX, assim como pela Convenção Americana de Direitos Humanos em seu artigo 13.1, que dispõe:

Art. 13.1 - Toda pessoa tem direito à liberdade de pensamento e de expressão. Esse direito compreende a liberdade de buscar, receber e difundir informações e ideias de toda natureza, sem consideração de fronteiras, verbalmente ou por escrito, ou em forma impressa ou artística, ou por qualquer outro processo de sua escolha.

Desde seu primeiro caso contencioso ${ }^{3}$, a Corte entende que a liberdade de expressão possui uma dimensão individual e uma social. Ou seja, a proteção da liberdade de expressão requer que ninguém seja arbitrariamente impedido de manifestar seu próprio pensamento, o que se refere a dimensão individual, assim como o direito coletivo de receber qualquer informação e de conhecer a expressão do pensamento alheio, referente à dimensão social (CorteIDH, 1985, 2001a). Ressalta-se que ambas as dimensões possuem igual importância e devem ser garantidas de forma simultânea para total efetividade ao direito à liberdade de expressão (CorteIDH, 2001a; 2001b).

No mesmo sentido complementa Spinoza (1997, p. 408) ao afirmar que em um Estado livre está permitido que cada um pense o que quer e diga o que pense, ao passo que os governos autoritários adotam medidas para sufocar ou limitar a manifestação do pensamento. Assim, é inegável a vinculação entre a democracia e a liberdade de expressão (BLUMLER; GUREVITCH, 1990 apud MACHADO, 2002, p. 260; SPINOZA, 1997, p. 408).

Para Natalia Ramos Nabuco de Araújo (2018, p. 23), o principal instrumento para o processo democrático é aquele que possibilita que o cidadão se inteire dos assuntos de interesse público. No mesmo sentido, Isabel Ferin afirma que:

A democracia supõe a existência de uma esfera pública onde se pressupõe a existência de um debate permanente sobre a res publica e a tomada de decisões que levem à sua gestão em benefício de todos. Um dos fatores estruturantes da esfera pública é a liberdade de expressão (FREIN, 2014, p. 11).

A liberdade de expressão é, portanto, uma pedra angular na própria existência de uma sociedade democrática, visto que é indispensável para a formação da opinião pública e para que a comunidade esteja bem informada no momento de tomar suas decisões. Deste modo, é possível afirmar que uma sociedade que não está bem informada não é plenamente livre (CorteIDH, 2004a). Isto porque é por meio do exercício deste direito que se pode garantir a transparência das atividades governamentais, a probidade, a responsabilidade dos

\footnotetext{
${ }^{3}$ Caso "A última tentação de Cristo" (Olmedo e outros) Vs. Chile. Sentença de 05 de fevereiro de 2001.
} 
governos na gestão pública e o respeito pelos direitos sociais, que são componentes fundamentais do exercício da democracia (OEA, 2001; CorteIDH, 2004a), assim como ficou definido no artigo 4 da Carta Democrática Interamericana (2001).

Desse modo, a liberdade de expressão é de suma importância para a sociedade. Entretanto, este não é um direito absoluto (OEA, 2001; CorteIDH, 2004a), ao passo que a liberdade de cada um tem por limites a liberdade e o direito dos outros (ARAÚJO, 2018, p. 34). Para a Corte, este direito é passível de restrições, desde que observados os requisitos previamente estabelecidos para tanto. Desta forma, a liberdade de expressão é a regra e a restrição é a exceção (CANOTILHO; MACHADO, 2003, p. 12), estando sujeita ao princípio da excepcionalidade e da ponderação proporcional de direitos e interesses constitucionalmente protegidos (MACHADO; BRITO, 2014, p. 32).

É pela análise destas restrições que se pode definir se o crime de desacato está de acordo com o entendimento da Corte acerca da liberdade de expressão, visto que a CorteIDH, admitindo que a liberdade de expressão não é um direito absoluto, define critérios para estabelecer se a restrição à liberdade de expressão é permitida e compatível com a Convenção Americana.

\title{
3 RESTRIÇÕES À LIBERDADE DE EXPRESSÃO
}

As possibilidades de restrição da liberdade de expressão estão previstas na própria Convenção Americana, em seu artigo 13.2. Nesse sentido:

\begin{abstract}
Art. 13.2 - O exercício do direito previsto no inciso precedente não pode estar sujeito a censura prévia, mas a responsabilidades ulteriores, que devem ser expressamente fixadas pela lei e ser necessárias para assegurar: a. o respeito aos direitos ou à reputação das demais pessoas; ou b. a proteção da segurança nacional, da ordem pública, ou da saúde ou da moral públicas (CorteIDH, 2004b).
\end{abstract}

O caso Herrera Ulloa Vs. Costa Rica (2004) foi primeiro caso contencioso em que a Corte abordou a questão da restrição da liberdade de expressão e analisou seus requisitos, afirmando que estas restrições se aplicam por meio das responsabilidades ulteriores pelo exercício abusivo do direito, não devendo esta limitação ir além do estritamente necessário, sob pena de se converter em um mecanismo de censura prévia, o que é estritamente proibido (CorteIDH, 2004a). 
Para a Corte Interamericana a determinação das responsabilidades ulteriores deve seguir certos requisitos: devem estar expressamente fixadas em lei; devem estar destinadas a proteger o direito à reputação, a segurança nacional, a ordem pública, a saúde ou a moral pública; e devem ser necessárias em uma sociedade democrática (CorteIDH, 2004a, 2004b, 2006, 2009b). Além disso, o Tribunal afirma que a necessidade e a legalidade das restrições dependerão de que estejam orientadas a satisfazer um interesse público imperativo (CorteIDH, 2004b). Para sustentar este argumento, a Corte se utiliza do entendimento do Tribunal Europeu de Direitos Humanos (TEDH), que versa sobre a liberdade de expressão. Nesse sentido:

A necessidade e a legalidade das restrições da liberdade de expressão fundadas sobre o artigo 13.2 da Convenção Americana dependerá de que estejam orientadas a satisfazer um interesse público imperativo. Entre várias opções para alcançar este objetivo, deve-se escolher aquela que restrinja em menor escala o direito protegido (CorteIDH, 1985; TEDH, 1979, 1985).

A Corte incorporou em suas sentenças o entendimento adotado na Opinião Consultiva n. 5/85, no sentido de que não é suficiente que se demonstre, por exemplo, que a lei cumpre um propósito útil ou oportuno. Assim, para que sejam compatíveis com a Convenção, as restrições devem se justificar segundo objetivos coletivos que, por sua importância, preponderem claramente sobre a necessidade social do pleno gozo do direito que o artigo 13 garante e não limitem mais do que o estritamente necessário o direito proclamado neste artigo. Isto é, a restrição deve ser proporcional ao interesse que a justifica e deve se ajustar estritamente ao alcance desse objetivo legítimo (CorteIDH, 1985).

Isto quer dizer que é necessário observar se o objetivo da restrição é relevante a ponto de gerar uma restrição à liberdade de expressão ou se irá gerar danos à sociedade democrática. Por exemplo, a censura prévia de espetáculos públicos a fím de resguardar a moral pública no que concerne à crianças e adolescentes é permitida (CorteIDH, 2001a), e seu fim visa um objetivo coletivo que é relevante para justificar a restrição, que é proporcional neste caso, visto que não restringe o direito além daquilo que é necessário.

Outro elemento que deve ser observado no momento de analisar a restrição da liberdade de expressão é o caráter de interesse público das manifestações, sendo esta proteção de assuntos de interesses públicos reafirmada pela Corte no caso Fontevecchia e D’Amico Vs. Argentina (2011) ao afirmar que a sociedade possui um interesse legítimo de se manter informada, sobretudo acerca situações que afetem direitos ou interesses gerais. 
No direito interno é possível observar a aplicação da restrição à liberdade de expressão no que se refere à tipificação dos crimes contra a honra no Código Penal Brasileiro, quando trata dos delitos de calúnia, injúria e difamação. Nestes casos, observa-se que a restrição é estabelecida em função da proteção da honra e da reputação, além de ser prevista em lei e de ser proporcional, pois se ajusta ao objetivo perseguido sem restringir por demasiado o direito à liberdade de expressão. Assim, tem-se a responsabilização posterior do indivíduo e não um caso de censura prévia.

Outra possibilidade de restrição permitida diz respeito ao discurso de ódio, que é definido como sendo a utilização de palavras que tendem a insultar, intimidar ou assediar pessoas em virtude de sua raça, cor, etnicidade, nacionalidade, sexo ou religião, ou, simplesmente, que têm capacidade de instigar violência, ódio ou discriminação (BRUGGER, 2007, p. 118).

Sobre o tema, o Supremo Tribunal Federal (STF) entendeu no caso Ellwagner, em sede do Habeas Corpus n. 82.424. 19/03/2004, que a garantia constitucional da liberdade de expressão não é absoluta, podendo ser afastada quando ultrapassar seus limites morais e jurídicos, como no caso de manifestações de conteúdo imoral que implicam ilicitude penal. Assim, no referido caso, que tratava da publicação e distribuição de material antissemita, a liberdade de expressão foi afastada em função da dignidade da pessoa humana.

Quando se trata do discurso de ódio, deve-se ter em conta seu caráter silenciador (WOLFSON, 1997, p. 2; FISS, 1996, p. 5-26), dessa maneira, além de configurar uma afronta ao direito à honra, um dos requisitos para a restrição da liberdade de expressão, também significa uma forma de impedir a manifestação alheia que por se sentir coibida, ou com medo, acaba por se calar. Nesse sentido, para proteger a liberdade de expressão dos demais e a própria dignidade, a restrição da liberdade de expressão no que se refere ao discurso de ódio está de acordo com o estabelecido na Convenção Americana e na jurisprudência da Corte Interamericana.

Desse modo, é possível restringir o direito à liberdade de expressão quando exercido de forma abusiva, sendo esta restrição aplicada por meio da responsabilização posterior do indivíduo, desde que obedecidos os requisitos definidos pela CorteIDH e pela Convenção Americana. 
Antes de analisar a relação entre o crime de desacato e sua possível incompatibilidade com a proteção da liberdade de expressão, é preciso analisar a via penal como meio de restrição da liberdade de expressão.

\subsection{O USO DA VIA PENAL COMO FORMA DE RESTRIÇÃO}

Para a Corte Interamericana, o direito penal é um meio mais restritivo e severo para se estabelecer a responsabilidade a respeito de uma conduta ilícita. Por isso, deve-se observar o princípio da intervenção mínima em razão da natureza do direito penal como última ratio (CorteIDH, 2004b, 2009b).

Por ser a mais severa, só deve ser aplicada em último caso, quando for de fato necessária. Em se tratando da restrição da liberdade de expressão isto pode ser posto em maior evidência, visto que a aplicação das punições penais, quando não sejam necessárias, adequadas ou proporcionais, podem se converter em um mecanismo de censura prévia, pois por medo de sofrer uma punição desproporcional o cidadão pode ser silenciado, o que representa um prejuízo à democracia e ao controle democrático das atividades estatais.

No mesmo sentido, Nucci (2014) entende que:

O princípio penal da intervenção mínima (ou da subsidiariedade), próprio e adequado ao Estado Democrático de Direito, exige que o Direito Penal constitua o braço estatal derradeiro para a solução dos conflitos emergentes em sociedade. Por isso, denomina-se, ainda, como a última opção (ultima ratio) do legislador para intervir, coercitivamente, impondo, quando necessário, a punição merecida ao infrator.

Portanto, em uma sociedade democrática o poder punitivo só deve ser exercido quando estritamente necessário (CorteIDH, 2009b). Apesar de a previsão em lei ser um requisito para restringir a liberdade de expressão, quando esta limitação se dá por meio da via penal, devem ser observados certos requisitos a fim de satisfazer o princípio da legalidade (CorteIDH, 2009a). Assim, a CorteIDH (2009a) entende que no momento da elaboração dos tipos penais é preciso utilizar termos específicos e inequívocos, para que não haja dúvidas acerca das condutas puníveis, para que não haja uma discricionariedade sem limites no momento da aplicação.

Ressalta-se que a Corte não considera contrária à Convenção Americana qualquer medida penal que restrinja a expressão de informações ou opiniões, pois isto iria de encontro com o estabelecido no artigo 13.2 e com a aplicação das responsabilidades posteriores, que 
também objetivam a proteção de direitos. Entretanto, deve ser analisada a necessidade da via penal para tutelar bens jurídicos fundamentais frente a condutas que impliquem em graves violações a estes bens (CorteIDH, 2009a).

Em outras palavras, deve ser analisada a gravidade da conduta praticada pelo emissor das manifestações, o dolo com que este atuou, as características do dano injustamente causado, e outros dados que demonstrem a absoluta necessidade de utilizar a via penal (CorteIDH, 2009a). Isto é, ao se analisar o delito de desacato, deve-se considerar se o dano causado, neste caso à honra, é suficiente para justificar a restrição de manifestações relevantes ao interesse público e à garantia da democracia.

Também deve ser analisada a proporcionalidade da medida penal empregada, de modo que o sacrifício resultante dela não seja desmedido frente às vantagens obtidas pela limitação (CorteIDH, 2009a), ou seja, se o objetivo que a restrição visa atingir não implica em um sacrifício desproporcional do direito que está sendo restringido.

Sobre esta restrição de direitos por meio da aplicação da via penal, pode-se observar como exemplo dois casos da Corte Interamericana: o caso Ricardo Canese Vs. Paraguai (2004) e o caso Palamara Iribarne Vs. Chile (2005).

No primeiro caso, a Corte entendeu que as sanções penais impostas constituíram uma punição desnecessária e excessiva pelas declarações que a suposta vítima emitiu no contexto da campanha eleitoral, a respeito de outro candidato à Presidência da República e sobre assuntos de interesse público, e também limitaram o debate aberto sobre temas de interesse ou preocupação pública e restringiram o exercício da liberdade de pensamento e de expressão. Neste caso, a Corte considerou que não existia um interesse social imperativo que justificasse a punição penal.

No segundo caso, a Corte analisou os requisitos da restrição à liberdade de expressão, bem como a maior proteção à manifestações que influem em questões de interesse público, concluindo que o uso da via penal foi desproporcional e não atendeu ao requisito de ser necessário em uma sociedade democrática, pois o senhor Palamara Iribarne foi privado do seu direito à liberdade de pensamento e expressão devido a opiniões críticas acerca de assuntos que se relacionavam diretamente com a forma com que as autoridades militares cumpriam suas funções. Devido à reforma legislativa ocorrida no Chile, adequando sua legislação, a Corte não aprofundou seu entendimento acerca do delito de desacato, apenas ressaltou que os Estados, assim como estabelece o artigo 2 da $\mathrm{CADH}$, devem adotar as 
medidas necessárias para garantir os direitos protegidos pela Convenção, o que implica na supressão tanto das medidas legislativas quanto práticas que impliquem na violação de tais direitos.

Após o estudo acerca da liberdade de expressão, das possibilidades de restrição desse direito, o que inclui a análise do uso da via penal como forma de restrição, pode-se passar à discussão sobre a compatibilidade da tipificação do crime de desacato com o entendimento da Corte Interamericana relativo à liberdade de expressão e suas restrições.

\section{A RELAÇÃO ENTRE O CRIME DE DESACATO E A LIBERDADE DE EXPRESSÃO}

O crime de desacato é tipificado na legislação brasileira no artigo 331 do Código Penal, que dispõe: "Desacatar funcionário público no exercício da função ou em razão dela". Desse modo, significa humilhar, ofender, desprestigiar ou desrespeitar, implicando algo injurioso (SALIM; AZEVEDO, 2012, p. 436), que tem por fim desacreditar a função pública (NUCCI, 2013, p. 609), ou seja, a conduta típica consiste em desacatar o funcionário público com a finalidade de ofender a dignidade e o prestígio da administração pública.

O objeto jurídico deste crime é a administração pública, nos seus interesses material e moral, isto é, no que concerne ao respeito ao Estado e ao funcionário público. Já seu objeto material seria o próprio funcionário público ofendido no exercício de sua função ou em razão dela. Portanto, seria um delito pluriofensivo (NUCCI, 2013, p. 609), cuja finalidade é a proteção da administração. Ressalta-se ainda que o dolo do agente no momento da ofensa é um elemento importante. Nesse sentido:

RECURSO EXTRAORDINÁRIO. MATÉRIA FÁTICA - INTERPRETAÇÃO
DE NORMAS LEGAIS. INVIABILIDADE. NEGATIVA DE SEGUIMENTO. 1.
O Colegiado de origem confirmou o entendimento do Juízo quanto à absolvição da
ré da imputação relativa ao delito de desacato, previsto no artigo 331 do Código
Penal, assentando não demonstrado o elemento volitivo do tipo. No extraordinário,
afirma o recorrente a violação dos artigos $2^{\circ}$ e $5^{\circ}$, incisos II e XXXIX, da
Constituição Federal. Argui a tipicidade do fato, considerado o dolo específico da
ré em desprezar a função pública exercida pelos policiais militares [...]. Confiram
a síntese do acórdão recorrido: APELAÇÃO-CRIME. DESACATO. ART. 331
DO CÓDIGO PENAL. AUSÊNCIA DE DOLO. SENTENÇA ABSOLUTÓRIA
CONFIRMADA. 1. Desacato. Prova judicializada que indica a ocorrência de
mera exaltação ou revolta momentânea, afastando o elemento volitiva do tipo,
consistente na vontade livre e consciente de praticar a ação ou de proferir
palavra injuriosa com o propósito de ofender ou de desrespeitar o funcionário
público. 2. Dolo específico. Mera enunciação de palavras em desabafo ou em
revolta momentânea não configura as elementares do tipo penal. 3 . Inexistente


adequação e dolo específico, impositiva a manutenção da absolvição da ré, por falta de provas. RECURSO MINISTERIAL DESPROVIDO. Ora, somente pela análise das provas constantes do processo seria dado concluir em sentido diverso, o que é vedado em sede extraordinária. A par desse aspecto, o acórdão impugnado revela interpretação de normas estritamente legais, em especial o artigo 331 do Código Penal, não ensejando campo ao acesso ao Supremo. À mercê de articulação sobre a violência à Carta da Republica, pretende-se submeter a análise matéria que não se enquadra no inciso III do artigo 102 da Constituição Federal. 3. Nego seguimento ao extraordinário. Deixo de fixar os honorários recursais previstos no artigo 85, § 11, do Código de Processo Civil de 2015, por tratar-se, na origem, de processo criminal, descabendo, portanto, a referida condenação. 4. Publiquem. Brasília, 16 de outubro de 2017. Ministro MARCO AURÉLIO (Relator). (grifo meu)

(STF - RE: 1081544 RS - RIO GRANDE DO SUL 0223881-22.2017.8.21.7000, Relator: Min. MARCO AURÉLIO, Data de Julgamento: 16/10/2017, Data de Publicação: DJe-238 19/10/2017)

Como dito anteriormente, a liberdade de expressão é essencial em uma sociedade democrática para garantir o pluralismo de ideias e o controle das atividades estatais, assim, o Estado deve impulsionar, sempre que possível, a maior participação, fomentando o pluralismo informativo, devendo ser guiado pela equidade (CorteIDH, 2011). Esta relação fica mais evidente quando se analisa as restrições da liberdade de expressão no que tange a manifestações de interesse público.

A Corte entende em sua Opinião Consultiva n. 5/85 que:

Em uma sociedade democrática, deve-se garantir as maiores possibilidades de circulação de notícias, ideias e opiniões, assim como o mais amplo acesso à informação por parte da sociedade. A liberdade de expressão se insere na ordem pública primária e radical da democracia, que não é concebível sem o debate livre e sem que a oposição tenha o pleno direito de se manifestar (tradução nossa).

Portanto, as manifestações divergentes refletem o pluralismo que existe dentro da sociedade e que deve ser garantido em função do respeito à própria democracia. Nesse sentido, mesmo as manifestações contrárias ao Estado devem ser asseguradas, pois integram o direito do indivíduo, dentro de uma sociedade democrática e plural, de se manifestar livremente e, por meio da difusão de ideias, buscar o cumprimento das obrigações estatais.

Acerca destas manifestações, a CorteIDH (2004a, 2004b) afirma que os assuntos de interesse público gozam de uma elevada esfera de proteção, devendo haver maior margem de tolerância frente a afirmações e apreciações feitas no curso dos debates políticos ou sobre questões de interesse público, pois este debate fomenta a construção da opinião pública e a informação da população, promovendo a responsabilidade do Estado e dos funcionários sobre sua gestão pública. 
Segundo o entendimento da CorteIDH no caso Ricardo Canese (2004b), as declarações concernentes a funcionários públicos ou a outras pessoas que exercem funções de natureza pública devem gozar, nos termos do artigo 13.2 da Convenção, de uma margem de abertura a um debate amplo a respeito de assuntos de interesse público, o que é essencial para o funcionamento de um sistema verdadeiramente democrático.

Neste caso, o senhor Ricardo Canese estava concorrendo nas eleições presidenciais do Paraguai e questionou a idoneidade e integridade do outro candidato à presidência por supostamente ter praticado atividades ilícitas. Esta declarações merecem uma maior margem de abertura por serem de interesse público, por serem relacionadas a uma pessoa que se postula como candidato à Presidência da República, a qual se submete voluntariamente ao escrutínio público, bem como a respeito de assuntos de interesse público nos quais a sociedade tem um legítimo interesse de se manter informada, de conhecer o que incide sobre o funcionamento do Estado, do que afeta interesses ou direitos gerais, ou lhe acarreta consequências importantes.

Assim, em se tratando de funcionários públicos, de pessoas que exercem funções de uma natureza pública e de políticos, deve-se aplicar um limite diferente de proteção, o qual não se assenta na qualidade do sujeito, mas no caráter de interesse público que implicam as atividades ou atuações de uma pessoa determinada. Isto porque, no entendimento da Corte, (2004b) as pessoas que influem em questões de interesse público se expuseram, voluntariamente, a um escrutínio público mais exigente e, consequentemente, nesse âmbito se veem submetidas a um maior risco de sofrerem críticas, já que suas atividades saem do domínio da esfera privada para se inserir na esfera do debate público.

Neste mesmo sentido, tem-se que o controle democrático dos órgãos do Estado pressupõe esta liberdade de opinião, em especial o cumprimento do ethos do funcionário e das regras que devem ser observadas pela opinião pública (KRIELE, 1980, p. 474), cuja violação deve dar lugar à indignação pública. Em outras palavras, a opinião pública e as críticas dos cidadãos aos funcionários públicos e ao serviço prestado por eles são um modo de exigir o cumprimento correto das obrigações dos mesmos, assim como do Estado.

Desse modo, observa-se que as manifestações que se enquadrariam no tipo penal do crime de desacato não estariam dirigidas a pessoa do funcionário público em si, isto é, não teriam o dolo específico de ofender sua honra, mas sim de criticar o Estado e o serviço público que estaria sendo prestado e que, naquele momento, estaria sendo exercido pelo 
funcionário em questão. Assim, a restrição da liberdade de expressão não se justificaria pela proteção do direito à honra, tão pouco pelo resguardo da administração pública, que deve garantir a livre manifestação, mesmo que contrária ou crítica.

Assim, no momento de se analisar a proporcionalidade e a necessidade da restrição, deve-se levar em conta que as manifestações neste caso não dizem respeito a questões privadas, mas a questões de interesse público. Neste sentido, o Tribunal Europeu (1992) entendeu que os limites das críticas são mais amplos em relação ao Estado que em relação a um indivíduo privado. Em um sistema democrático, as ações ou omissões do Estado devem estar sujeitas a um escrutínio rigoroso, não só por parte das autoridades legislativas e judiciais, mas também por parte da imprensa e da opinião pública.

Estas considerações não significam, de nenhum modo, que a honra dos funcionários públicos ou das pessoas públicas não deve ser juridicamente protegida, mas deve sê-lo de maneira acorde com os princípios do pluralismo democrático (CorteIDH, 2004b). Além disso, o direito à honra é protegido pela Convenção Americana em seu artigo 11 e pela Corte Interamericana que discorre acerca deste direito em sua jurisprudência, inclusive ao tratar da liberdade de expressão, afirmando que ambos os direitos estão protegidos pela Convenção, devendo ser tutelados, bem como coexistir de forma harmoniosa (2009a).

Como exemplo, pode-se citar o caso Usón Ramirez Vs. Venezuela (2009), que versa acerca da condenação do senhor Ramirez a uma pena de 5 anos e 2 meses pelo delito de injúria contra a Força Armada Nacional. Neste caso, a Corte esclareceu a respeito da proteção do direito à honra, afirmando que a proteção deste direito implica limites nas ingerências dos particulares e do Estado, por isso, é legítimo que quem se sinta afetado em sua honra recorra aos mecanismos judiciais que o Estado disponha para sua proteção.

Em relação ao direito interno, a Corte (2011) entende que a lei deve estabelecer as restrições à liberdade de expressão e somente para alcançar os fins estabelecidos pela Convenção Americana, devendo ser necessariamente expressa e taxativa, além de que os juízes e órgãos vinculados à administração da justiça em todos os níveis têm a obrigação de exercer ex officio o controle de convencionalidade entre as normas internas e a Convenção Americana, evidentemente observando suas respectivas competências e o regulamento processual correspondente.

A questão do desacato e de sua compatibilidade com a Convenção Americana já foi discutida pelo Superior Tribunal de Justiça (STJ) em duas decisões controversas: o Recurso 
Especial n. 1.640.084 - SP (2016/0032106-0), em que o STJ entende pela incompatibilidade do crime com a Convenção Americana e, em seguida, o Habeas Corpus n. 379269 / MS (2016/0303542-3) que possui entendimento contrário.

No Recurso Especial, o STJ afirmou que o crime de desacato era incompatível com a Convenção por proporcionar maior nível de proteção aos agentes de Estado em detrimento dos particulares, contrariando o princípio democrático e igualitário. Apesar de nessa decisão o Superior Tribunal de Justiça citar a Comissão Interamericana e a Convenção Americana, o Tribunal não se utiliza dos conceitos e dos requisitos apresentados pelo Sistema Interamericano como parâmetro para analisar o delito de desacato e sua compatibilidade com o direito à liberdade de expressão.

Além disso, o STJ ressalta que na legislação brasileira existem outros tipos penais que visam a proteção da honra, como os crimes de calúnia, difamação e injúria, que visam a responsabilização posterior pelo exercício abusivo do direito à liberdade de expressão. A diferença é que estes tipos penais, apesar de também restringirem o direito à liberdade de expressão, não implicam na restrição de manifestações a respeito de funcionários públicos ou assuntos de interesse público, portanto, não geram um sacrifício desproporcional em face das vantagens que visa obter (CorteIDH, 2009a), cumprindo com os requisitos elencados pela CorteIDH.

No Habeas Corpus em sede de Mandado de Segurança (HC n. 379269 / MS 2016/0303542-3), o STJ utiliza como argumentos: o fato da CorteIDH não possuir uma jurisprudência acerca do delito de desacato; afirma que o crime de desacato está de acordo com as restrições permitidas da liberdade de expressão; e o fato de que mesmo que a Corte possuísse jurisprudência acerca do tema, o Estado brasileiro não seria obrigado a respeitá-la em face de sua soberania.

Em primeiro lugar, o fato de não existir na jurisprudência da Corte um caso que verse sobre o delito de desacato no Brasil não elide a aplicação do entendimento formulado em sua jurisprudência para dirimir a questão aqui apresentada. Ocorre que a Corte não teve a oportunidade de aprofundar seu entendimento acerca do delito de desacato, estando este presente apenas na análise relativa ao princípio da legalidade e da proporcionalidade e necessidade do uso a via penal. Entretanto, isto não significa que o entendimento relativo à liberdade de expressão presente na jurisprudência da Corte não possa ser aplicado. 
Além disso, não se pode afirmar que a tipificação do delito de desacato cumpre com os requisitos para a restrição da liberdade de expressão, pois apesar de apresentar uma restrição que é prevista em lei, que tem o intuito de proteger a honra e a ordem pública, esta limitação não satisfaz o requisito da necessidade social imperiosa e da busca por um interesse coletivo, pois para isso a restrição deve ser necessária em uma sociedade democrática.

Neste sentido, a proteção da honra não seria suficiente para justificar a restrição da liberdade de expressão no presente caso, pois isto significaria impor à sociedade prejuízos maiores que a vantagem perseguida pela tipificação do delito. O crime de desacato também não satisfaz os requisitos de necessidade e de proporcionalidade, pois como já ressaltado a via penal, por ser o meio mais severo de punição, deve ser o último recurso utilizado. Desse modo, o crime de desacato não cumpre com os requisitos elencados pela Convenção Americana e pela Jurisprudência da Corte, pois estabelece uma medida desproporcional que restringe as manifestações de interesse público, necessárias em uma sociedade democrática.

\section{CONSIDERAÇÕES FINAIS}

A liberdade de expressão é fundamental em uma sociedade democrática, visto que é por meio do exercício dela, tanto em sua dimensão social quanto em sua dimensão individual, que a sociedade consegue manifestar suas ideias e se manter informada, contribuindo para a formação da opinião pública e para o controle das atividades estatais.

Apesar de não ser um direito absoluto, como prevê a própria jurisprudência da Corte Interamericana e também a Convenção Americana, devem ser obedecidos certos critérios para que sua restrição não implique na violação do direito. A restrição deve prevista em lei, deve estar destinadas a proteger o direito à reputação, a segurança nacional, a ordem pública, a saúde ou a moral pública, deve ser necessárias em uma sociedade democrática, e deve atender o requisito da proporcionalidade, em especial quando a restrição se dá por meio do uso da via penal.

É, neste contexto, que se enquadra a relação do delito de desacato com a liberdade de expressão, pois além de ser uma forma de limitar a livre manifestação, a tipificação do delito diz respeito à manifestações acerca de funcionários públicos, que segundo a jurisprudência da Corte Interamericana possuem maior grau de proteção, devido sua importância para a formação da opinião pública e para o controle democrático. Desse modo, a restrição imposta 
público não é suficiente para justificar o dano causado à liberdade de expressão neste caso, não justificando a restrição de manifestações relevantes ao interesse público e à garantia da democracia.

Além disso, existem no direito interno outras formas de proteção do direito à honra, como os crimes de calúnia, difamação e injúria, que não visam a restrição específica de manifestações de interesse público.

O Tribunal interno, ao analisar a compatibilidade do desacato com o artigo 13 da Convenção, apesar de fazer referência a entendimentos provenientes do Sistema Interamericano, não se aprofundou no estudo das sentenças da Corte acerca da liberdade de expressão, bem como não buscou analisar os requisitos para a restrição deste direito.

Portanto, ao apresentar uma restrição desproporcional e que não se apresenta como necessária em uma sociedade democrático, além de não cumprir com os demais requisitos elencados pela Convenção e pela Corte, pode-se dizer que o crime de desacato é incompatível com a proteção do direito à liberdade de expressão nos termos da jurisprudência do Sistema Interamericano.

\section{REFERÊNCIAS}

ARAUJO, Natalia Ramos Nabuco de. Liberdade de Expressão e Discurso de Ódio. Curitiba: Juruá, 2018.

BRASIL. Superior Tribunal de Justiça. Recurso Especial n. 1.640.084 SP (2016/0032106-0), Recorrente: Alex Carlos Gomes. Relator: Ministro Ribeiro Dantas. São Paulo, 2016.

BRASIL. Superior Tribunal de Justiça. Terceira Seção. Habeas Corpus n. 379269 / Mandado de Segurança (2016/0303542-3). Paciente: Magno Leandro Santos Angelino. Relator: Reynaldo Soares da Fonseca. Julgamento: 24/05/2017, Publicação: 30/06/2017.

BRASIL. Supremo Tribunal Federal. Habeas Corpus n. 82.424. Paciente: Siegfried Ellwagner. Relator: Ministro Moreira Alves. Rio Grande do Sul. Julgamento: 17/09/2003, Publicação: 19/03/2004.

BRASIL. Supremo Tribunal Federal. Recurso Especial n. 1081544. Rio Grande do Sul 0223881-22.2017.8.21.7000. Relator: Ministro Marco Aurélio. Julgamento: 16/10/2017, Publicação: 19/10/2017.

BRUGGER, Winfried. Proibição ou Proteção do Discurso de Ódio? Algumas Observações sobre o Direito Alemão e o Americano. Revista de Direito Público. Tradução de Maria Ângela Jardim Oliveira, 2007. 
CANOTILHO, J. J. Gomes; MACHADO, Jónatas. Reality Shows e Liberdade de Propagação. Coimbra: Coimbra, 2003.

CHEUQER, Cláudio. A Liberdade de Expressão como Direito Fundamental Prima Facie: análise crítica e proposta de revisão ao padrão jurisprudencial brasileiro. Rio de Janeiro, Lumen Juris, 2011.

CoreIDH. Caso Herrera Ulloa Vs. Costa Rica. Exceções Preliminares, Mérito, Reparações e Custas. Sentença de 02 de julho de 2004.

Caso "A Última Tentação de Cristo" Vs. Chile. Mérito, Reparações e Custas. Sentença de 05 de fevereiro de 2001.

Caso Fontevecchia e D'Amico Vs. Argentina. Mérito, Reparações e Custas. Sentença de 29 de novembro de 2011.

Caso Ivcher Bronstein e outros Vs. Peru. Mérito, Reparações e Custas. Sentença de 06 de fevereiro de 2001.

Caso Kimel Vs. Argentina. Mérito, Reparações e Custas. Sentença de 20 de novembro de 2009.

Caso Palamara Iribarne Vs. Chile. Mérito, Reparações e Custas. Sentença de 22 de novembro de 2005.

Caso Ricardo Canese Vs. Paraguai. Mérito, Reparações e Custas. Sentença de 31 de agosto de 2004.

Caso Usón Ramírez Vs. Venezuela. Exceção Preliminar, Mérito, Reparações e Custas. Sentença de 20 de novembro de 2009.

La Colegiación Obligatoria de Periodistas. Opinião Consultiva OC-5/85 de 13 de novembro de 1985.

FERIN, Isabel. Diálogos sobre Censura e Liberdade de Expressão. Brasil $e$ Portugal/organização Maria Cristina Castilho Costa. São Paulo: ECA/USP, 2014.

FISS, Owen. The Irony of Free Speech. Cambridge: Harvard University Press, 1996, p. 5-26.

KRIELE. Martin. Introdición a la teoría del Estado: Fundamentos Históricos de la Legitimidad del Estado Constitucional Democrático. Traducción por Eugenio Bulygin. Buenos Aires: De Palma, 1980.

MACHADO, Jónatas. Liberdade de Expressão. Dimensões Constitucionais da Esfera Pública no Sistema Social. Coimbra: Coimbra, 2002.

MACHADO, Jónatas; BRITO, Iolanda Rodrigues de. Bibliografia Não Autorizada versus Liberdade de Expressão. Curitiba: Juruá, 2014. 
FERREIRA, Pinto. Comentários à Constituição Brasileira. v. 7. São Paulo: Saraiva, 1989.

NUCCI, Guilherme de Souza. A intervenção mínima no âmbito penal e o Estado Democrático de Direito. Guilherme Nucci, 2014. Disponível em: http://www.guilhermenucci.com.br/artigo/intervencao-minima-ambito-penal-e-o-estadodemocratico-de-direito-2 Acesso em: 09 set. 2020.

NUCCI, Guilherme de Souza. Código Penal Comentado. 2. ed. São Paulo: Revista dos Tribunais, 2013.

OEA. Carta Democrática Interamericana. 11 de setembro de 2001.

OEA. Marco Jurídico Interamericano sobre o Direito à Liberdade de Expressão. Comissão Interamericana de Direitos Humanos. Relatoria Especial para a Liberdade de Expressão. 30 de dezembro de 2009.

PIOVESAN, Flávia. Direitos Humanos e Justiça Internacional. 6 ed. rev., ampl., e atual. São Paulo: Saraiva. 2015.

SALIM, Alexandre; AZEVEDO, Marcelo André de. Direito Penal. 2. ed. Salvador: JusPODIVM, 2012.

SEN, Amartya. Prefácio ao livro Pathologies of Power, de Paul Farmer. 22 de novembro de 2004.

SPINOZA, Baruch de. Tratado Teológico-Político. Tradução de Atilano Dmínguez. Altaya, 1997.

TEDH. Caso Barthold Vs. Germany, 1985.

TEDH. Caso Castells Vs. Spain, 1992.

TEDH. Caso The Sunday Times Vs. United Kingdom, 1979.

WOLFSON, Nicholas. Hate speech, sex speech, free speech. Westport: Conn. 1997. 